MATHEMATICA, 60 (83), $\mathrm{N}^{\circ}$ 1, 2018, pp. 32-47

\title{
REFINING LAH-RIBARIĆ INTEGRAL INEQUALITY FOR DIVISIONS OF MEASURABLE SPACE
}

\author{
SILVESTRU SEVER DRAGOMIR
}

\begin{abstract}
In this paper, we establish some refinements of Lah-Ribarić inequality for the general Lebesgue integral on divisions of measurable space. Applications for discrete inequalities and weighted means of positive numbers are also given. Some examples related to Hermite-Hadamard inequality for convex functions are provided as well.
\end{abstract}

MSC 2010. Primary 26D15; Secondary 26D10.

Key words. Jensen's inequality, convex functions, Lebesgue integral, weighted means, Lah-Ribarić inequality, special means.

\section{REFERENCES}

[1] S. Abramovich, S. Ivelić and J. Pečarić, Generalizations of Jensen-Steffensen and related integral inequalities for superquadratic functions, CEJOR Cent. Eur. J. Oper. Res., 8 (2010), 937-949.

[2] S.S. Dragomir, Some remarks on Hadamard's inequalities for convex functions, Extracta Math., 9 (1994), 88-94.

[3] S.S. Dragomir, An improvement of Jensen's inequality, Bull. Math. Soc. Sci. Math. Roumanie (N.S.), 34 (82) (1990), 291-296.

[4] S.S. Dragomir, Some refinements of Ky Fan's inequality, J. Math. Anal. Appl., 163 (1992), 317-321.

[5] S.S. Dragomir, Some refinements of Jensen's inequality, J. Math. Anal. Appl., 168 (1992), 518-522.

[6] S.S. Dragomir, A further improvement of Jensen's inequality, Tamkang J. Math., 25 (1994), 29-36.

[7] S.S. Dragomir, A new improvement of Jensen's inequality, Indian J. Pure Appl. Math., 26 (1995), 959-968.

[8] S.S. Dragomir, A refinement of Jensen's inequality with applications for $f$-divergence measures, Taiwanese J. Math., 14 (2010), 153-164.

[9] S.S. Dragomir, A new refinement of Jensen's inequality in linear spaces with applications, Mathematical and Computer Modelling, 52 (2010), 1497-1505.

[10] S.S. Dragomir, Some reverses of the Jensen inequality with applications, Bull. Aust. Math. Soc.,87 (2013), 177-194.

[11] S.S. Dragomir and N.M. Ionescu, Some converse of Jensen's inequality and applications, J. Numer. Anal. Approx. Theory, 23 (1994), 71-78.

[12] S.S. Dragomir and C.J. Goh, A counterpart of Jensen's discrete inequality for differentialble convex mappings and applications in information theory, Mathematical and Computer Modelling, 24 (1996), 1-11.

DOI: $10.24193 /$ mathcluj.2018.1.04 
[13] S.S. Dragomir and M.A. Khan, Refinement of the Jensen integral inequality, Research Group in Mathematical Inequalities and Applications, Research Report Collection, 18, Article 94 (2015), 1-10.

[14] S.S. Dragomir, Refining Jensen's integral inequality for divisions of measurable space, Research Group in Mathematical Inequalities and Applications, Research Report Collection, 18, Article 97 (2015), 1-14.

[15] S.S. Dragomir and C.E.M. Pearce, Selected Topics on Hermite-Hadamard Inequalities and Applications, Research Group in Mathematical Inequalities and Applications, Monographs, Victoria University, 2000.

[16] S.S. Dragomir, J. Pečarić and L.E. Persson, Properties of some functionals related to Jensen's inequality, Acta Math. Hungar., 70 (1996), 129-143.

[17] L. Hortháth, Inequalities corresponding to the classical Jensen's inequality, Journal of Mathematical Inequalities, 3 (2009), 189-200.

[18] L. Hortháth, A refinement of the integral form of Jensen's inequality, J. Inequal. Appl., 2012, Article 178 (2012), 1-19.

[19] S. Khalid and J. Pečarić, On the refinement of the integral Jensen-Steffensen inequality, J. Inequal. Appl., 2013, Article 20 (2013), 1-18.

[20] P. Lah and M. Ribarič, Converse of Jensen's inequality for convex functions, Publikacije Elektrotehničkog fakulteta, Serija Matematika i fizika, 412/460 (1973), 201-205.

[21] J. Pečarić and S.S. Dragomir, A refinements of Jensen inequality and applications, Stud. Univ. Babes-Bolyai Math., 24 (1989), 15-19.

[22] F. Qi and M.L. Yang, Comparisons of two integral inequalities with Hermite-HadamardJensen's integral inequality, Research Group in Mathematical Inequalities and Applications, Research report collection, 8 (2005), 1-6.

[23] Z.Y. Song, Discussion on the integral type Jensen inequality for P-convex functions (in Chinese), Pure Appl. Math. (Xi'an), 28 (2012), 36-40.

Received July 28, 2017

Accepted August 23, 2017
Victoria University

Mathematics, College of Engineering 8 Science

PO Box 14428

Melbourne City, MC 8001, Australia

University of the Witwatersrand

School of Computer Science \& Applied Mathematics

Private Bag 3, Johannesburg 2050, South Africa

E-mail: sever.dragomir@vu.edu.au 